\title{
Methylphenidate and indomethacin induced visual hallucination: a case report
}

\author{
Kemal Utku Yazici ${ }^{1 \oplus}$, Ipek Percinel Yazici ${ }^{1}$ \\ 'Firat University, Faculty of Medicine, Department of Child and Adolescent Psychiatry, Elazig - Turkey
}

\section{Dear Editor,}

Attention deficit hyperactivity disorder (ADHD) is one of the most common neuropsychiatric disorders seen in childhood and adolescence. Psychopharmacologic agents are known to be the most effective treatment options for ADHD. The most frequently researched and prescribed drug group in this regard is psychostimulants (1). Methylphenidate is the most commonly used stimulant for the treatment of ADHD (2). Indomethacin, a nonsteroidal anti-inflammatory drug (NSAID), is a non-selective inhibitor of cyclooxygenase 1 and cyclooxygenase 2 enzymes, which play a role in prostaglandin synthesis from arachidonic acid (3). Indomethacin is quite often used as an antiinflammatory and analgesic drug.

A 14-year-old girl was admitted to our clinic with complaints of attention deficit, lack of concentration in school lessons, forgetfulness, procrastination, lack of being organized, excessive talking, and impulsivity. As a result of our assessments, the patient was diagnosed with ADHD, and $27 \mathrm{mg} /$ day of long-acting methylphenidate treatment was initiated. The case was followed regularly in our policlinic. The methylphenidate dose was increased to $36 \mathrm{mg} /$ day after one month in view of moderate benefit of the treatment and absence of any side effects. No drug-related problems were identified in controls performed within two months after the dose increase. Then, the patient presented outside the scheduled follow-up appointments with the complaint of "seeing strange things." She reported that while sitting at home, she had seen very short strange creatures resembling dwarves with non-human faces. Those creatures looked hostile to her and laughed at her after talking among themselves. The complaints had begun about 48 hours prior to her admission to the hospital. From that time, she could not stay at home alone. The patient had been using long-acting methylphenidate for a total of three months when she presented to us with psychotic symptoms. She did not have any psychiatric or organic disease in her medical history and her family history. According to the information obtained from her family, she had experienced menarche four days ago and she was using indomethacin in the last three days due to intense dysmenorrhea. The patient's mother stated that she had also given her daughter indomethacin several times for complaints such as headache or abdominal pain before she started treatment with methylphenidate. However, no complications were observed at those times when the drug was given. There was no other report of disease, trauma, or drug use. There was no disorder that could cause psychotic findings in the organic examinations of the patient. Her current psychotic complaints, which had been treated regularly with methylphenidate therapy for about three months without showing any side effects associated with methylphenidate, were thought to be related to the subsequent use of indomethacin. The patient, having benefited from methylphenidate treatment, was recommended to stop using indomethacin. The methylphenidate treatment was continued as before. After cessation of indomethacin,

How to cite this article: Yazici KU, Percinel Yazici I. Methylphenidate- and indomethacin-induced visual hallucination: a case report. Dusunen Adam The Journal of Psychiatry and Neurological Sciences 2019;32:368-370.

Correspondence: Kemal Utku Yazici, Firat University, Faculty of Medicine, Department of Child and Adolescent Psychiatry, Elazig - Turkey 
the patient's visual hallucinations quickly disappeared (within 48 hours). The psychotic symptoms did not recur in the clinical follow-up period.

Methylphenidate has been used for many years in an effective and reliable way in the treatment of ADHD during childhood and adolescence. In general, methylphenidate is quite well tolerated. Side effects most commonly reported with methylphenidate treatment are loss of appetite, insomnia, and irritability. The side effects are mostly mild and temporary (4).

Besides mild and temporary side effects, there are also studies in the literature that have reported psychotic findings related to the use of methylphenidate. Visual, auditory, and tactile hallucinations during treatment with methylphenidate at therapeutic doses have been found (5-9). Psychotic symptoms thought to be associated with methylphenidate have been seen rarely, usually with acute onset, and disappeared in a short period of time after cessation of medication (8). In a meta-analysis reviewing 49 randomized controlled trials, psychotic/manic symptoms were observed in 11 out of 743 cases using drugs for ADHD treatment (the rate per 100 person-years in the pooled active drug group was 1.48). There were no psychotic/manic symptoms in $420 \mathrm{ADHD}$ patients receiving the placebo treatment. The most common psychotic/manic symptoms were observed in the treatment of transdermal methylphenidate and dexamphetamine, respectively (10). In another study reviewing medical records from the period between 2001 and 2014, psychotic symptoms were observed in only 103 out of 20,322 patients between ages of 6 and 19 years that had received methylphenidate therapy during this time (11). It is not exactly known how methylphenidate caused the psychotic symptoms. The basic effect mechanism of methylphenidate is to increase dopamine levels in the synaptic gap (12). It has been indicated that this increase may be a risk factor for psychotic symptoms, and that methylphenidate may cause psychotic symptoms this way (13).

Indomethacin, an NSAID agent, is often used as an analgesic treatment option. There are studies in the literature reporting psychotic symptoms induced by NSAIDs (14). There have also been publications indicating psychotic symptoms during indomethacin use (15-17). Although the underlying mechanisms of psychotic symptoms due to indomethacin have not been fully understood, indomethacin has been documented to inhibit prostaglandin synthesis and thus increase dopamine levels indirectly, which may cause psychotic symptoms (18).
Although it has been suggested in the literature that psychotic symptoms associated with methylphenidate usually begin shortly after starting the drug, some studies have noted that psychotic symptoms can also be observed after months or years of methylphenidate use $(5,8)$. No psychotic findings were observed when our patient used only methylphenidate. Visual hallucinations emerged during the period when indomethacin was being used to treat dysmenorrhea (she had been using methylphenidate for about three months). In addition, it was learned from her family that the patient sometimes had used indomethacin for a short time (max. 1 week) also before using methylphenidate and experienced no problem. Moreover, psychotic symptoms quickly disappeared only after cessation of indomethacin therapy. The psychotic side effects observed in our case may be associated only with the use of indomethacin. However, the current situation makes us think that simultaneous use of both drugs may strengthen their mutual influence on psychotic side effects; although they did not cause such a problem when used individually. This possibility is crucial in terms of clinical practice.

Methylphenidate increases the level of dopamine in the synaptic gap (12). Indomethacin has also been reported to increase dopamine levels indirectly by inhibiting prostaglandin synthesis (18). These two drugs might potentially affect each other, increase the dopamine level further, and thus cause psychotic symptoms. In our case, no psychotic side effect was observed in the period when methylphenidate and indomethacin were used separately, but visual hallucinations appeared when they were used together. As far as we know, this was the first reported case that has demonstrated psychotic symptoms due to concurrent use of both agents.

In conclusion, in rare cases, drug-drug interactions can lead to dangerous situations for patients. It is vital for clinicians to pay attention to this possibility in the presence of severe psychiatric symptoms that occur during unexpected situations. In this regard, our study is considered to be important. However, there is a need for further detailed studies in order to clarify this issue.

Conflict of Interest: All authors declared that there is no conflict of interest.

Financial Disclosure: No funding declared.

\section{REFERENCES}

1. Kaplan G, Newcorn JH. Pharmacotherapy for child and adolescent attention-deficit hyperactivity disorder. Pediatr Clin North Am 2011; 58:99-120. [CrossRef] 
2. Sharma A, Couture J. A review of the pathophysiology, etiology, and treatment of attention-deficit hyperactivity disorder (ADHD). Ann Pharmacother 2014; 48:209-225. [CrossRef]

3. Vane JR, Botting RM. Mechanism of action of anti-inflammatory drugs. Scand J Rheumatol Suppl 1996; 102:9-21. [CrossRef]

4. Clavenna A, Bonati M. Pediatric pharmacoepidemiology - safety and effectiveness of medicines for ADHD. Expert Opin Drug Saf 2017; 16:1335-1345. [CrossRef]

5. Gross-Tsur V, Joseph A, Shalev RS. Hallucinations during methylphenidate therapy. Neurology 2004; 63:753-754. [CrossRef]

6. Ross RG. Psychotic and manic-like symptoms during stimulant treatment of attention deficit hyperactivity disorder. Am J Psychiatry 2006; 163:1149-1152. [CrossRef]

7. Halevy A, Shuper A. Methylphenidate induction of complex visual hallucinations. J Child Neurol 2009; 24:1005-1007. [CrossRef]

8. Porfirio MC, Giana G, GiovinazzoS, Curatolo P. Methylphenidateinduced visual hallucinations. Neuropediatrics 2011; 42:30-31.

9. Martinez-Aguayo JC, Arancibia M, Meza-Concha N, Bustamante C, Perez-Bracchiglione J, Madrid E. Brief psychosis induced by methylphenidate in a child with attention deficit disorder: a case report and literature review. Medwave 2017; 17:e6980. [CrossRef]

10. Mosholder AD, Gelperin K, Hammad TA, Phelan K, JohannLiang R. Hallucinations and other psychotic symptoms associated with the use of attention-deficit/hyperactivity disorder drugs in children. Pediatrics 2009; 123:611-616. [CrossRef]
11. Man KK, Coghill D, Chan EW, Lau WC, Hollis C, Liddle E, Banaschewski T, McCarthy S, Neubert A, Sayal K, Ip P, Wong IC. Methylphenidate and the risk of psychotic disorders and hallucinations in children and adolescents in a large health system. Transl Psychiatry 2016; 6:e956. [CrossRef]

12. Volkow ND, Wang G, Fowler JS, Logan J, Gerasimov M, Maynard L, Ding Y, Gatley SJ, Gifford A, Franceschi D. Therapeutic doses of oral methylphenidate significantly increase extracellular dopamine in the human brain. J Neurosci 2001; 21:RC121.

13. Groenman AP, Schweren LJ, Dietrich A, Hoekstra PJ. An update on the safety of psychostimulants for the treatment of attentiondeficit/hyperactivity disorder. Expert Opin Drug Saf 2017; 16:455-464. [CrossRef]

14. Onder G, Pellicciotti F, Gambassi G, Bernabei R. NSAID-related psychiatric adverse events: who is at risk? Drugs 2004; 64:26192627. [CrossRef]

15. Braddock LE, Heard RN. Visual hallucinations due to indomethacin: a case report. Int Clin Psychopharmacol 1986; 1:263-266. [CrossRef]

16. Tharumaratnam D, Bashford S, Khan SA. Indomethacin induced psychosis. Postgrad Med J 2000; 76:736-737. [CrossRef]

17. Turkoglu G, Turkoglu S, Kayal S, Karahan AY. IndomethacinInduced Psychotic Disorder. Clin Neuropharmacol 2016; 39:161.

18. Ross BM, Brooks RJ, Lee M, Kalasinsky KS, Vorce SP, Seeman M, Fletcher PJ, Turenne SD. Cyclooxygenase inhibitor modulation of dopamine-related behaviours. Eur J Pharmacol 2002; 450:141-151. 